\title{
Does the medical insurance system play a real role in reducing catastrophic economic burden in elderly patients with cardiovascular disease in China? Implication for accurately targeting vulnerable characteristics
}

Meiyan Ma ${ }^{1}$, Wanxin Tian ${ }^{1}$, Jian Kang ${ }^{2}$, Yuze Li ${ }^{3}$, Qi Xia ${ }^{1}$, Nianshi Wang ${ }^{1}$, Wenqing Miao ${ }^{1}$, Xiyu Zhang ${ }^{1}$, Yiyun Zhang ${ }^{4}$, Baoguo Shi ${ }^{5}$, Han Gao ${ }^{6}$, Tao Sun ${ }^{7}$, Xuelian Fu', Yanhua Hao ${ }^{1}$, Heng Li ${ }^{9}$, Linghan Shan ${ }^{1 *}$, Qunhong $\mathrm{Wu}^{1 *}$ and $\mathrm{Ye} \mathrm{Li}{ }^{1^{*}}$

\begin{abstract}
Background: The vulnerability of cardiovascular disease (CVD) patients' health abilities, combined with the severity of the disease and the overlapping risk factors, leads such people to bear the economic burden of the disease due to the medical services. We estimated the economic burden of CVD and identified the weak link in the design of the medical insurance.

Methods: Data from 5610 middle-aged and elderly with CVD were drawn from the 2015 wave of "China Health and Retirement Longitudinal Study" (CHARLS). The recommended method of the "World Health Organization" (WHO) was adopted to calculate "catastrophic health expenditure" (CHE), "impoverishment by medical expenses" (IME), and applied the treatment-effect model to analyze the determinants of CHE.

Results: The incidence of CHE was 19.9\% for the elderly families with CVD members, which was 3.6\% higher than for uninsured families (16.3\%). Families with CVD combined with $>3$ other chronic diseases (38.88\%) were the riskiest factor for the high CHE in the new rural cooperative medical system (NCMS). Moreover, families with members > 75 years old (33.33\%), having two chronic disease (30.74\%), and families having disabled members (33.33\%), hospitalization members (32.41\%) were identified as the high risky determinants for the high CHE in NCMS.

(Continued on next page)
\end{abstract}

\footnotetext{
*Correspondence: liye8459@163.com; wuqunhong@163.com;

linghanshan@126.com

${ }^{1}$ Research Center of Public Policy and Management, School of Health Management, Harbin Medical University, Harbin 150086, Heilongjiang, China

Full list of author information is available at the end of the article
}

C C The Author(s). 2021 Open Access This article is licensed under a Creative Commons Attribution 4.0 International License, which permits use, sharing, adaptation, distribution and reproduction in any medium or format, as long as you give appropriate credit to the original author(s) and the source, provide a link to the Creative Commons licence, and indicate if changes were made. The images or other third party material in this article are included in the article's Creative Commons. licence, unless indicated otherwise in a credit line to the material. If material is not included in the article's Creative Commons licence and your intended use is not permitted by statutory regulation or exceeds the permitted use, you will need to obtain permission directly from the copyright holder. To view a copy of this licence, visit http://creativecommons.org/licenses/by/4.0/ The Creative Commons Public Domain Dedication waiver (http://creativecommons.org/publicdomain/zero/1.0/) applies to the data made available in this article, unless otherwise stated in a credit line to the data. 
(Continued from previous page)

Conclusions: Elderly with physical vulnerabilities were more prone to CHE. The medical insurance only reduced barriers to accessing health resources for elderly with CVD; however it lacked the policy inclination for highutilization populations, and had poorly accurate identification of the vulnerable characteristics of CVD, which in turn affects the economic protection ability of the medical insurance. The dispersion between the multiple medical security schemes leads to the existence of blind spots in the economic risk protection of individuals and families.

Keywords: Cardiovascular disease, Catastrophic health expenditure, Impoverishment by medical expense, Medical insurance, Health policy, China

\section{Highlights}

- Older groups with physical vulnerability are more prone to catastrophic health expenditures.

- The medical insurance only guarantees the basic health utilization threshold for elderly with CVD, lacks policy inclination for high-utilization populations, and has poorly accurate identification of vulnerable characteristics, which in turn affects the economic protection ability of the medical insurance for patients with CVD.

- The unclosed connection between the multiple medical security systems leads to the existence of blind spots in the economic risk protection of individuals and families.

\section{Introduction}

Aging, rapid urbanization, and shifting disease patterns are causing cardiovascular disease (CVD) to become established as one of the primary diseases in the worl $\mathrm{d}[1,2]$. Worldwide, roughly 17.9 million people die of CVD each year, and the absolute number of deaths from chronic CVD increased by $42.4 \%$ between 1990 and 2015 (2017) [3, 4]. The incidence and mortality of CVD are also serious in China. As of 2015, 290 million people were suffering from CVD in China, including more than 9.5 million cases of heart disease [5]. Between 1990 and 2013, the total number of CVD deaths increased by $46 \%$ in China, mainly due to population aging [6]. The increasing trend of CVD has brought a heavy economic burden to the world at a global the population and householdlevel [7]. It is estimated that as of 2015, the estimated annual global cost of CVD is expected to increase by $16 \%$, from $\$ 906$ billion to more than $\$ 1$ trillion by 2030 [8]. In India, $25 \%$ of families with a member with CVD experience catastrophic expenditure, and 10\% are driven into poverty [9].

The particularity of the internal disease structure and the characteristics of the elderly have made China a country with a high incidence of CVD. In China, the disability-adjusted life years (DALY) caused by CVD has reached 582.255 million, accounting for roughly $20 \%$ of the world's CVD, which is nearly 9\% higher than the international average [10]. Annual inpatient care cost has risen at a steady rate of 30\% since 2004 [11]. Compared to Western Europe, China suffers a 50\% higher mortality rate from CVD and faces a larger economic burden [12]. Annual direct medical expenses for CVDs in China are more than 130 billion yuan, accounting for more than $22 \%$ of the total medical expenses in China during the same period, which is $10 \%$ higher than that of Australia [13]. Research indicates that during the 30 years from 2010 to 2040, the annual economic benefits of reducing cardiovascular mortality by $1 \%$ in China is equivalent to $68 \%$ of the real GDP in 2010, exceeding US\$ 10.7 trillion [14].

China's basic medical insurance system consists of three types of medical insurance schemes: urban employees' insurance medical (MIUE), urban resident insurance medical (MIUR), and the new rural cooperative medical system (NCMS) [15]. The basic medical insurance for economic protection has two basic goals: first, to ensure that all people have access to high-quality care; and second, that everyone has the ability to pay for these services to maintain and improve their health [16]. The coverage of China's medical insurance not only includes common diseases but also provides a certain extent of protection for sudden infectious diseases such as malaria and COVID-19 [17-20], which can reduce the family medical economic burden in multiple directions.

China has achieved 95\% coverage of medical and health services. However, the inefficiency of the healthcare system and the uneven distribution of medical resources make the cost-effectiveness of continuous medical reforms lower, and the coverage and depth of the medical insurance system need to be improved. Studies have demonstrated that the actual effect of this coverage has been offset by the rapid escalation of medical expenses, especially for the elderly group that combines age and disease [21]. One study measured the disease burden of CVD patients aged 60 years and older in 2011-2013 and found that the direct and indirect medical costs of residents rose from 4938 yuan to 5717 yuan, and the out-of-pocket (OOP) increased by roughly 12 percentage points (from 58.1 to $70 \%$ ) [22]. The resident's medical insurance 
reimbursement ratio is substantially lower than that of the European Union's (EU) major disease reimbursement ratio of not less than 60\% [23]. The World Health Organization (WHO) reports that a reasonable OOP is 15-20\% [24]. Once the literature exceeds the prescribed warning value, it will often cause vulnerable groups, such as rural residents and the elderly with low economic incomes, to fall into excessive cash health expenditures, resulting in "impoverishment by medical expenses" and "returning from poverty."

These studies indicate that the vulnerability of CVD patients' health abilities, combined with the severity and recurrence of the disease itself and the overlapping risk factors, leads them to bear the heavy economic burden of the disease due to the use of medical services. However, to our knowledge, the existing literature largely focuses on the whole population, and no studies target this particularly vulnerable group. Moreover, in previous studies, logistic regression was typically used to study the determinants of catastrophic health expenditure (CHE), ignoring the simultaneous causal relationship between potential unobservable variables and endogenous variables. To obtain more explanatory results, we applied the treatment-effect model and instrumental variable (IV) method to explore the influencing factors. We adopted the method recommended by the WHO to verify the health-reducing effect of the health care system, that is, whether the medical insurance system reduces the risk of CHE in cardiovascular patients over the age of 45 years. It aimed to capture the vulnerable characteristics that are prone to CHE and diagnoses the weak policy link that fails to eliminate CHE. It is important to understand whether the medical insurance system increases the accessibility and affordability of health care, which provides good evidence for further ways to alleviate health poverty.

\section{Methods}

\section{Data source and sampling method}

The data used to calculate the rates of CHE and impoverishment by medical expenses (IME) were obtained from the 2015 China Health and Pension Tracking Survey (CHARLS) database, which is designed to collect microscopic information from $>45$-year-olds. CHARLS covers 450 communities in 150 counties from 28 of 32 provinces in mainland China. Face-to-face household interviews were conducted by qualified investigators. Households were randomly selected from maps and listings within each rural or urban community by fourstage stratified cluster sampling to select eligible individuals. Data were collected through questionnaires, and quality control was implemented by supervisors and included GPS comparison, data verification, recording verification, and telephone verification. A total of 5610 samples (2507 households) were finally obtained after excluding incomplete data and missing values.

\section{Statistical analysis \\ Calculation method for CHE and IME}

The WHO's recommended method was adopted to calculate CHE and IME [25]. CHE was defined as an OOP payment for health care equal to or exceeding $40 \%$ of a household's capacity to pay. IME was defined as consumption expenditure equal to or higher than household subsistence expenditure but lower than the subsistence expenditure (SE) net of OOP health payments. The key expenditure indicators involved in the calculation process are as follows:

$$
\text { Equivalent family size }: \text { eqsize }_{h}=\text { hhsize }_{h}^{0.56}
$$

Equivalent food expenditure: total household food expenditure divided by equivalent family size

$$
\text { eqfood }_{h}=\frac{\text { food }_{h}}{\text { eqsize }_{h}}
$$

Poverty Line (pl): the weighted average food expenditure of a household, whose food expenditure as a share of household consumption expenditure fell between the 45th and 55th percentiles of the entire sample.

$$
p l=\frac{\sum w_{h} * e q f o o d_{h}}{\sum w_{h}}
$$

Household subsistence expenditure (SE) was calculated using food expenditure as a share of total household consumption expenditure.

$$
s e_{h}=p l * e q s i z e_{h}
$$

A household's capacity to pay (CTP) was defined as non-subsistence spending of a household as a share of total household consumption expenditure.

$$
\begin{aligned}
& c t p_{h}=\exp _{h}-s e_{h} \text { if } \mathrm{se}_{\mathrm{h}} \leq \text { food }_{\mathrm{h}} \\
& c t p_{h}=\exp _{h}-\text { food }_{h} \text { if } \mathrm{se}_{\mathrm{h}}>\text { food }_{\mathrm{h}}
\end{aligned}
$$

Out-of-pocket (OOP) health expenditure: The payments made by households for their health services without third-party compensation.

$$
\operatorname{oopctp}_{h}=\frac{o o p_{h}}{c t p_{h}}
$$

Household consumption expenditure (exp) comprises both monetary and in-kind payments on all goods and services and the money value of the consumption of home-made products.

The consumption quintile is ranked by equivalized per capita household consumption expenditure weighted 
with the standard household size rather than the actual household scale.

$$
\text { eq } \exp _{h}=\exp _{h} / \text { eqsize }_{h}
$$

\section{Treatment effect model}

Relationship between participating in the medical insurance system and CHE is characterized by a joint causal relationship. There are implicit selection biases in participating in the medical insurance system, such as the average community participation rate, selfassessment of health status, and other unobserved characteristics associated with the initial selection. To address the bias caused by hidden selectivity bias and joint causality, we applied an IV method called the therapeutic effect model [26, 27].

\section{Instrument indicators}

We assume that the indicators of medical insurance are endogenous. To address this endogeneity, we required IVs, which are related to endogenous predictors (medical insurance) but are not related to the error term of outcome variables (CHE) [28]. The premise of using the IV method is that there are endogenous variables in the regression equation. Therefore, it is necessary to identify endogenous variables (whether there was participation in medical insurance) in the regression equation. In our study, we verify this problem using the DWH test. In other words, the DWH test checks whether the endogenous predictor is truly endogenous. (The heterogeneity test result shows that $P=0.000<0.05$, so we use the DWH text)

By reviewing existing literature, two possible instruments were initially identified: self-assessment of health status and average community participation rate. Selfreported poorly healthy groups are more likely to choose to take medical insurance to maintain their health [29]. The average community participation rate of residents' basic medical insurance will have an impact on the willingness of families to participate in insurance. People living in the same community have certain common characteristics, such as family economic level and health management awareness, which will make them participate in medical insurance. Moreover, the basic medical insurance plan in China is a community or companybased unit. For example, the MIUE is driven by the company, and the NCMS is that the village cadres mobilize the villagers to participate in the medical insurance scheme, so that the community participation rate is highly correlated with the willingness to participate in the family [30].

Good instruments should satisfy two main criteria: relevance and validity. That is, good instruments would be correlated with the endogenous variable (relevance criterion) but not with the error terms in the model of the outcome variable (validity criterion).

The overidentification test and GMM regression are used to check the validity and relevance [31,32]. To further investigate the weak IV problem, we also performed redundancy tests. The results indicate that the community participation rate became our ultimate effective instrumental variable. The results regarding the validity and relevance are presented in Table 1.

The treatment effect model includes a two-stage regression. In the first phase, we regress the outcome variables of the covariates (the heterogeneity test results reveal that $P=0.000<0.05$, so we use 'Generalized method of moments' (GMM) as our regression equation). Based on the results of the first phase, we add instrument variables and the outcome variable performs a quadratic regression.

\section{Outcome variable}

We created a binary indicator for CHE as the outcome variable ( $1=$ occurrence, $0=$ no occurrence).

\section{Covariates}

In our study, we used three sets of information as covariates: (1) social-demographic characteristics, specifically age, gender, marital status, education level of household head, family size, and having a member over 65 years old; (2) health status of family members, including whether the household has at least one member with a chronic disease, who has been admitted to the hospital, or has a disability; (3) demand and utilization of health services for household heads, mainly including hospitalization rate, outpatient rate, and non-admission rate (defined as the percentage of patients who need to be hospitalized but are not hospitalized).

\section{Results \\ Sample characteristics}

Table 2 summarizes the characteristics of CVD in 2015. The total sample comprised 2507 households and 5610 individuals, of which $50.2 \%$ of household heads with

Table 1 Validity test and correlation test

\begin{tabular}{lllll}
\hline Instrumental variable & DWH test & Over-identification test & F test & Redundancy test \\
\hline Community participation rate & chi2 $(1)=4.5588$ & chi2 $(1)=1.6578$ & $\mathbf{F}=\mathbf{2 4 . 3 0 3 4}>\mathbf{1 0}$ & Chi-sq. $(1)=\mathbf{0 . 0 0 0 0 ^ { * }}$ \\
Self-assessed health & $(p=0.0327<0.05)^{*}$ & $(\boldsymbol{p}=\mathbf{0 . 1 9 7 9}>\mathbf{0 . 0 5})^{*}$ & & Chi-sq.(1) $=0.3873$ \\
\hline
\end{tabular}

DWH test, ${ }^{*} p<0.05$; Over-identification test, ${ }^{*} p>0.05$; Redundancy test, ${ }^{*} p<0.05$ 
Table 2 Patients' demographic characteristics

\begin{tabular}{|c|c|c|}
\hline Variables & Variable value & $\begin{array}{l}\text { Percentage } \\
\text { (\%) }\end{array}$ \\
\hline \multirow[t]{2}{*}{$\mathrm{CHE}$} & No & 80.1 \\
\hline & Yes & 19.9 \\
\hline \multirow{2}{*}{$\begin{array}{l}\text { Participate in medical } \\
\text { insurance scheme }\end{array}$} & No & 2.9 \\
\hline & Yes & 97.1 \\
\hline \multirow[t]{2}{*}{ Gender of household head } & Female & 49.8 \\
\hline & Male & 50.2 \\
\hline \multirow{2}{*}{$\begin{array}{l}\text { Marital status of household } \\
\text { head }\end{array}$} & Others & 15.0 \\
\hline & Married & 85.0 \\
\hline \multirow{3}{*}{$\begin{array}{l}\text { Education level of } \\
\text { household head }\end{array}$} & Illiteracy & 21.5 \\
\hline & Elementary to junior high & 59.4 \\
\hline & High school and above & 15.4 \\
\hline \multirow[t]{3}{*}{ Family size } & 1 & 62.6 \\
\hline & $2-3$ & 31.9 \\
\hline & More than 3 people & 5.5 \\
\hline \multirow[t]{4}{*}{ Age of household head } & $45-54$ & 32.5 \\
\hline & $55-64$ & 33.2 \\
\hline & $65-74$ & 23.5 \\
\hline & More than75years old & 8.7 \\
\hline \multirow{2}{*}{$\begin{array}{l}\text { Having members over } \\
65 \text { years old }\end{array}$} & No & 44.2 \\
\hline & Yes & 54.0 \\
\hline \multirow{4}{*}{$\begin{array}{l}\text { Combined with other } \\
\text { chronic diseases }\end{array}$} & No & 39.6 \\
\hline & 1 & 35.5 \\
\hline & 2 & 21.3 \\
\hline & 3 & 3.6 \\
\hline \multirow[t]{2}{*}{ Having hospitalized members } & No & 87.1 \\
\hline & Yes & 12.2 \\
\hline \multirow[t]{2}{*}{ Having disabled members } & No & 3.1 \\
\hline & Yes & 92.3 \\
\hline \multirow[t]{5}{*}{ Health satisfaction } & Very good & 4.2 \\
\hline & Good & 19.1 \\
\hline & Fair & 48.8 \\
\hline & Poor & 20.5 \\
\hline & Very poor & 6.8 \\
\hline \multirow{5}{*}{$\begin{array}{l}\text { Household consumption } \\
\text { per capital quintile }\end{array}$} & Lowest & 20.7 \\
\hline & 2 & 21.3 \\
\hline & 3 & 19.9 \\
\hline & 4 & 20.2 \\
\hline & Highest & 17.9 \\
\hline \multirow[t]{3}{*}{ Region } & Eastern & 33.7 \\
\hline & Middle & 46.3 \\
\hline & Western & 20.0 \\
\hline \multirow[t]{2}{*}{ location } & Rural & 75.1 \\
\hline & Urban & 24.9 \\
\hline
\end{tabular}

CVD were male, and around $65.7 \%$ of the elderly were aged $<64$. Over $59.4 \%$ had an elementary to junior high education level, only $23.3 \%$ of CVD patients had a health satisfaction status of "good," with $>60.4 \%$ having one or more other chronic diseases. Furthermore, $97.1 \%$ of the CVD patients had medical insurance.

\section{Health care needs and service utilization (Table 3)}

Regarding health service utilization for the high-risk group of elderly patients with CVD, the rate of monthly prevalence was $11.4 \%$ overall. A higher proportion of patients with CVD used inpatient services (14.8\%), and more than $19.8 \%$ of respondents reported the utilization of outpatient services over the past month. The above indicators demonstrate different trends for different populations with CVDs as follows (Table 3):

Cardiovascular patients with a high level of health service demand but low utilization of health services and low reimbursement rates. For example, families with CVD and $>3$ other chronic diseases had a high demand for health services. Its prevalence and hospitalization rates were 13.8 and $23.5 \%$, respectively. However, the health service utilization (non-admission rate 9.8\%) and the reimbursement level (48.5\%) were lower than those of CVD patients without other chronic diseases.

In terms of family economic level and type of medical insurance, cardiovascular patients with a high level of health service demand and high health utilization but low reimbursement. Household heads of CVDs with NCMS had a higher prevalence (14.3\%) and outpatient rate $(20.5 \%)$, but the hospitalization reimbursement ratio (39.7\%) was lower by nearly 30\% than MIUE (69.8\%). Patients who participated in MIUR of CVDs demonstrated a similar pattern. Notably, among the wealthiest households with CVDs, the hospitalization and visit rates were 16.4 and $20.9 \%$, respectively, but the hospitalization reimbursement ratio was only $49.2 \%$, less than $50 \%$.

\section{CHE and IME in different households (Table 4)}

We further measured the incidence of CHE and IME in elderly patients with CVD, and $19.9 \%$ of all interviewed CVD patients encountered CHE, and the IME occurred in $7.6 \%$ of the overall population (Table 4).

We also found that as the family size increased for CVD patients, the risk of households being trapped in $\mathrm{CHE}$ and IME was reduced. For example, the incidence of CHE among households with one person $(8.1 \%)$ was twice that of those without other diseases (14.7\%). Furthermore, families with inpatients and disability members of CVD increased the risk of CHE and had a greater financial burden, and the incidence of CHE was 29.3 and $31.1 \%$, which was more than $10 \%$ higher than that of those without inpatients and disability members of CVD (18.6 and 19.5\%, respectively). 
Table 3 Health care demand, service utilization, and reimbursement of household head

\begin{tabular}{|c|c|c|c|c|c|}
\hline & Prevalence (\%) & $\begin{array}{l}\text { Hospitalization } \\
\text { rate }(\%)\end{array}$ & $\begin{array}{l}\text { Outpatient } \\
\text { rate }(\%)\end{array}$ & $\begin{array}{l}\text { Non-admission } \\
\text { rate }(\%)\end{array}$ & $\begin{array}{l}\text { Hospitalization } \\
\text { reimbursement ratio (\%) }\end{array}$ \\
\hline \multicolumn{6}{|l|}{ Family size } \\
\hline 1 & 14.1 & 15.6 & 19.8 & 6.3 & 41.1 \\
\hline $2-3$ & 13.6 & 13.5 & 19.3 & 5.7 & 52.8 \\
\hline More than 3 people & 13.8 & 14.7 & 24.0 & 8.3 & 49.1 \\
\hline \multicolumn{6}{|l|}{ Hospitalization members } \\
\hline Yes & 24.7 & / & 34.2 & 13.1 & 44.6 \\
\hline No & 12.3 & / & 17.3 & 5.0 & / \\
\hline \multicolumn{6}{|l|}{ Having disabled members } \\
\hline Yes & 21.7 & 17.2 & 21.8 & 9.9 & 40.3 \\
\hline No & 13.4 & 14.6 & 19.6 & 5.8 & 46.0 \\
\hline \multicolumn{6}{|l|}{ Combined with other chronic diseases } \\
\hline No & 12.0 & 13.3 & 17.7 & 5.3 & 45.3 \\
\hline 1 & 14.0 & 15.3 & 20.8 & 6.0 & 46.8 \\
\hline 2 & 16.6 & 14.6 & 20.0 & 7.4 & 49.1 \\
\hline$\geqq 3$ & 13.8 & 23.5 & 24.5 & 9.8 & 48.5 \\
\hline \multicolumn{6}{|l|}{ Medical insurance schemes } \\
\hline MIUE & $8.6 \%$ & 20.4 & 20.0 & 3.3 & 69.8 \\
\hline MIUR & 15.5 & 18.4 & 19.1 & 8.5 & 52.0 \\
\hline NCMS & 14.3 & 13.7 & 20.5 & 6.6 & 39.7 \\
\hline Integrated insurance & 14.7 & 16.3 & 23.3 & 4.7 & 54.2 \\
\hline Others and not having insurance & 13.0 & 13.5 & 14.3 & 7.2 & 59.2 \\
\hline \multicolumn{6}{|l|}{ Economic quintile } \\
\hline Lowest & 13.1 & 14.9 & 19.9 & 6.3 & 41.8 \\
\hline 2 & 12.4 & 14.8 & 19.5 & 6.2 & 42.5 \\
\hline 3 & 14.2 & 13.4 & 19.6 & 5.2 & 38.3 \\
\hline 4 & 15.8 & 14.8 & 19.6 & 6.8 & 42.7 \\
\hline Highest & 14.0 & 16.4 & 20.9 & 6.5 & 49.2 \\
\hline Overall & 11.4 & 14.8 & 19.8 & 6.2 & 44.5 \\
\hline
\end{tabular}

Income level was not the main reason for the high incidence of CHE in patients with CVD. Among them, sub-poor families with CVD had the highest incidence rate of CHE (22.5\%) and health expenditure burden (22.1\%), which was higher than the richest households with CVD. Regarding the type of insurance, among the three basic medical insurances, cardiovascular families with NCMS had the greatest economic burden of disease, and the risk of CHE was also the highest (21.6\%), nearly $8.3 \%$ higher than that of NIUE (13.3\%).

Treatment-effect model for patients with CVD (Table 5) Community participation rate was added as an effective instrumental variable to the treatment-effect model. The results were as follows: family size, health satisfaction, combination with other chronic diseases, having hospitalization members, having disabled members, and participating in insurance were all found to be significantly associated with the odds of encountering $\mathrm{CHE}$ with CVD $(P<0.05)$.

\section{Social demographic perspective}

The incidence of CHE and family size with CVD have developed in reverse: as the cardiovascular family grows in size, the risk of CHE is reduced by 4.99 percentage points.

\section{Health needs and utilization perspective}

Combined with other chronic diseases, health satisfaction, having hospitalization members, and having disabled members had a positive correlation with the risk of CHE in cardiovascular patients, and with an increase in combining other chronic diseases or hospitalization 
Table 4 CHE, and IME in different households

\begin{tabular}{|c|c|c|c|}
\hline & $\begin{array}{l}\text { Incidence } \\
\text { of CHE (\%) }\end{array}$ & $\begin{array}{l}\text { Incidence } \\
\text { of IME (\%) }\end{array}$ & $\begin{array}{l}\text { OOP/CTP } \\
\text { (\%) }\end{array}$ \\
\hline \multicolumn{4}{|l|}{ Family size } \\
\hline 1 & 22.6 & 8.6 & 21.1 \\
\hline $2-3$ & 15.6 & 6.2 & 13.7 \\
\hline More than 3 people & 14.4 & 3.6 & 12.8 \\
\hline \multicolumn{4}{|l|}{ Hospitalization members } \\
\hline Yes & 29.3 & 8.7 & 28.4 \\
\hline No & 18.6 & 7.5 & 15.6 \\
\hline \multicolumn{4}{|l|}{ Having disability members } \\
\hline Yes & 31.1 & 10.3 & 35.6 \\
\hline No & 19.5 & 7.4 & 16.7 \\
\hline \multicolumn{4}{|l|}{ Health satisfaction } \\
\hline Very good & 17.1 & 4.1 & 17.0 \\
\hline Good & 17.3 & 5.8 & 17.5 \\
\hline Fair & 17.5 & 7.7 & 14.1 \\
\hline Poor & 24.4 & 8.5 & 21.7 \\
\hline Very poor & 30.5 & 10.0 & 25.3 \\
\hline \multicolumn{4}{|c|}{ Combine other chronic diseases } \\
\hline No & 14.7 & 6.1 & 14.6 \\
\hline 1 & 20.2 & 6.8 & 18.8 \\
\hline 2 & 27.0 & 10.5 & 19.2 \\
\hline$\geqq 3$ & 31.8 & 14.2 & 22.8 \\
\hline \multicolumn{4}{|l|}{ Medical insurance } \\
\hline MIUE & 13.3 & 3.1 & 13.0 \\
\hline MIUR & 15.1 & 4.5 & 13.8 \\
\hline NCMS & 21.6 & 9.0 & 19.7 \\
\hline Integrated insurance & 20.5 & 5.1 & 6.1 \\
\hline $\begin{array}{l}\text { Others and not having } \\
\text { insurance }\end{array}$ & 16.3 & 3.8 & 15.3 \\
\hline \multicolumn{4}{|c|}{ Household consumption per capital quintile } \\
\hline Lowest & 19.3 & 8.3 & 17.9 \\
\hline 2 & 22.5 & 10.1 & 22.1 \\
\hline 3 & 20.4 & 7.8 & 18.4 \\
\hline 4 & 19.5 & 5.9 & 16.2 \\
\hline Highest & 17.5 & 5.5 & 13.6 \\
\hline \multicolumn{4}{|l|}{ Overall } \\
\hline / & 19.9 & 7.6 & 17.2 \\
\hline
\end{tabular}

members increased, the risk of a family's CHE increased by 4.68 and $10.01 \%$, respectively.

\section{Medical insurance perspective}

Cardiovascular patients participating in medical insurance increased the risk of $\mathrm{CHE}$ and increased the risk of being trapped in CHE by $28.9 \%$.

\section{Medical insurance level}

As shown in the above figure, among patients with CVD, the rural population accounted for $75.1 \%$ of the sample size, and the CHE of NCMS was the riskiest, at $21.6 \%$. Moreover, the treatment-effect model demonstrates that the probability of $\mathrm{CHE}$ participating in health insurance families with CVD has increased by $29.8 \%$. Therefore, to identify the NCMS of key bottlenecks, we conducted a specific influencing factor analysis and found that families with CVD combined with $>3$ other chronic diseases (38.88\%) were the primary cause of high CHE in NCMS. Next, in turn, being more than 75 years old (33.33\%), having disabled members (33.33\%), having hospitalization members $(32.41 \%)$, and combining two chronic diseases (30.74\%) were the top five factors influencing the high CHE of families with CVD in NCMS. The results are presented in Fig. 1.

\section{Discussion}

The proportion of households associated with CHE and IME in elderly patients with CVD were 19.9 and 7.6\%, respectively. These rates were higher than those of developed countries but were lower than those of low-income countries [33, 34]. The incidence of $\mathrm{CHE}$ participating in medical insurance was $3.6 \%$ higher than that of uninsured households (16.3\%). Families with CVD have a substantially higher risk of IME than families without CVD (7.0\%) and the overall population (7.2\%). CVD patients' risk tolerance for health care payments is lower than the average in China. Simultaneously, our study also found that cardiovascular families with chronic patients, inpatients, and disabled members are at a higher risk of falling into poverty because of the cost of health care, and they are becoming a stubborn group with a high burden of CVD under the medical insurance system.

As a vulnerable group, patients with CVD are mainly characterized as a high-risk group that integrates physiological, social, and health factors. It is important to identify the risk factors for patients with CVD and identify vulnerable groups to better play the economic protection role of the medical insurance system. As mentioned earlier, despite these government efforts, many disadvantaged groups are not considered target populations for benefit enhancement. Through comprehensive analysis, we found that the disadvantaged elderly population with mental health has the following characteristics:

\section{Older groups with physical vulnerability are more prone to $\mathrm{CHE}$}

First, age growth, loss of healthy capital, and decline in physiology are inevitable for the elderly. However, elderly people are at a disadvantage in accessing resources and fail to enjoy social welfare policies fairly $[35,36]$. For example, the incidence of CHE in elderly people aged over 75 years in the NCMS was $33.33 \%$, second only to the merger of 
Table 5 Results of treatment-effect model for patients with CVD

\begin{tabular}{|c|c|c|c|c|c|c|}
\hline & Coef. & Std. Err. & $\mathbf{z}$ & $P>|z|$ & 95\% C.I. & \\
\hline \multicolumn{7}{|l|}{ CHE } \\
\hline Marital status of household head & 0.0129 & 0.0233 & 0.53 & 0.599 & -0.0335 & 0.0581 \\
\hline Region & -0.0209 & 0.0116 & -1.79 & 0.073 & -0.0438 & 0.0019 \\
\hline Gender of household head & 0.0081 & 0.0174 & -0.47 & 0.640 & -0.0424 & 0.0261 \\
\hline Education level of household head & 0.0016 & 0.0151 & 0.11 & 0.915 & -0.0281 & 0.0313 \\
\hline Household consumption per capital quintile & -0.0069 & 0.0061 & -1.12 & 0.262 & -0.0190 & 0.0052 \\
\hline Family size & -0.0499 & 0.0138 & -3.61 & 0.000 & -0.0770 & -0.0227 \\
\hline Urban and rural & -0.0379 & 0.0203 & -1.86 & 0.063 & -0.0779 & 0.0019 \\
\hline Health satisfaction & 0.0246 & 0.0093 & 2.64 & 0.008 & 0.0063 & 0.0429 \\
\hline Having disabled members & 0.0961 & 0.0473 & 2.03 & 0.042 & 0.0033 & 0.1889 \\
\hline Having members over 65 years old & 0.0129 & 0.0171 & 0.76 & 0.450 & -0.0206 & 0.0465 \\
\hline Combined with other chronic diseases & 0.0468 & 0.0088 & 5.32 & 0.000 & 0.0296 & 0.0641 \\
\hline Having hospitalized members & 0.1001 & 0.0252 & 3.97 & 0.000 & 0.0506 & 0.1495 \\
\hline Having insurance & 0.2895 & 0.1454 & 1.99 & 0.047 & 0.0044 & 0.5745 \\
\hline \multicolumn{7}{|l|}{ Having insurance } \\
\hline Community participation rate & 0.0571 & 0.0056 & 10.08 & 0.000 & 0.0460 & 0.0682 \\
\hline
\end{tabular}

Coef Coefficient, Std. Err standard error of the mean, 95\% C.I Confidence Interval

three chronic diseases (33.88\%). The WHO reported that $23 \%$ of the world's disease burden is on older people, and chronic non-communicable diseases have a major impact on this burden [37]. Furthermore, the morbidity and concurrency of elderly patients with CVD may eventually lead to premature death and disability, while long-term health care costs, drug costs, and rehabilitation cost greatly increase the risk of CHE [38]. Our results indicate that the hospitalization rate $(23.5 \%)$, rate of visits $(24.5 \%)$, and incidence of CHE (31.8\%) of patients with more than three

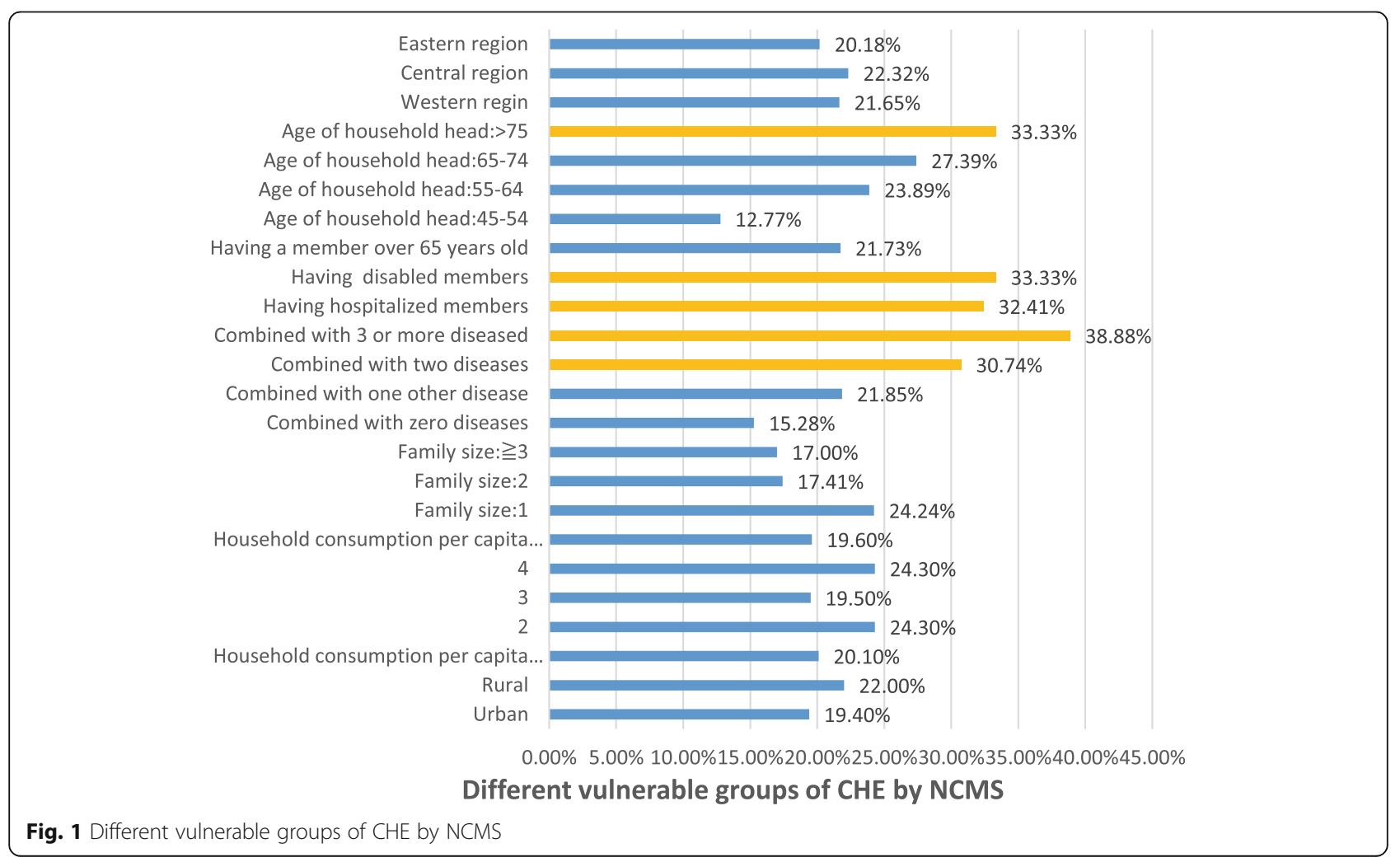


chronic diseases are far higher than those without chronic diseases (13.3, 17.7, 14.7\%, respectively), and the treatmenteffect model showed that the combination with other chronic diseases increased the risk of CHE by $4.68 \%$. Past evidence has demonstrated that the likelihood of using health care (e.g., hospitalization) increases in the presence of chronic or multiple conditions [39]. With the increase in the number of chronic diseases, the addition of other chronic diseases will prolong the hospitalization time on the basis of the original single disease, which will cause CVD patients to superimpose the cost of other diseases when they bear the economic pressure from their CVD burden. Studies have found that $1 / 3$ of adults have multiple chronic diseases, equivalent to $3 / 4$ of the elderly in developed countries [40]. Therefore, suffering from a variety of chronic diseases has become a major health problem for the elderly in the future, greatly increasing the risk of CHE.

The medical insurance system only guarantees the basic health utilization threshold for elderly patients with CVD and lacks policy inclination for high-utilization populations

The existing medical insurance system reduces the threshold of health service utilization for vulnerable groups. Such as those with CVDs, but it only achieves the first goal of medical insurance-that is, to ensure that all people have access to high-quality care. Our results indicate that the incidence of CHE for high-demand people with inpatients and disabled patients is substantially higher than that of the normal population. In our study, families with disabled patients had a higher prevalence $(21.7 \%)$ and outpatient rates $(21.8 \%)$ than those without disabilities (13.4 and 19.6\%, respectively). However, the hospitalization reimbursement ratio was only $40.6 \%$, far below the overall level (44.5\%), and OOP accounted for $35.6 \%$ of total household health expenses, which is substantially higher than that of OECD countries [41]. A study in South Korea revealed that families with disabilities face higher CHE than those without people with disabilities, and annual living expenses for OOP medical expenses are roughly 1.2 to 1.4 times greater [42]. This may be due to physical or mental disability in disabled patients leading to job loss or reduced earnings, while higher medical care needs due to disability increase the burden of high medical costs [43]. Even relatively small expenditures are catastrophic for poor families, and excessive OOP health care spending can lead to poverty [44].

The medical insurance system has poorly accurate identification of vulnerable characteristics, which in turn affects the economic protection ability of the medical insurance system for patients with cardiovascular diseases

China's medical insurance policy aims to solve the problem of "people falling into poverty due to illnesses" and to ensure that most people are not reduced to poverty because of health-related issues. However, our results indicate that the risk of CHE for CVD patients participating in medical insurance schemes has increased by 28.9\%, which had the highest incidence of CHE for NCMS. The medical insurance system has the disadvantage of insufficient protection of policies in reducing the economic burden of residents' medical care and maintaining residents' health rights and health. China's health sector reform has achieved unprecedented progress, but protecting vulnerable groups from healthcare-related impoverishment remains a challenge. The goal of full coverage has been achieved, and the financing level of NCMS has improved. By 2019, the annual premium increased from 30RMB (US\$3.62) in 2003 to 740 RMB (US\$105.7) per person, with 520 RMB (US\$74.3) from central and local governments, and 220 RMB (US\$31.4) from households [45]. Although the reimbursement rates of NCMS vary across counties and especially provinces, its reimbursement level of the scheme has significantly improved since the initial stage [46]. However, for the poor, the elderly, the patients with CVD, or the groups with multiple vulnerabilities, the improvement in risk pooling and government subsidies of NCMS may be offset by the increasing medical expenses [47, 48]. Several scholars also called for a more generous package to improve the security capacity of the NCMS pursuing the CHE and IME reduction in the short term [49]. However, simply increasing the reimbursement rate is not feasible in the long-term as it may lead to the insolvency of the medical insurance fund and have a more longterm negative impact on the insured members [50]. Specifically, it is important to adopt a comprehensive governance strategy that includes reconsidering benefit packages, redesigning social health care insurance programs, and controlling the price of medical services to further protect vulnerable groups such as the elderly population with CVD.

\section{Inequality between types of health insurance systems: binary urban and rural structure divided by place of residence}

The household registration system in China directly affects the ability to obtain various medical benefits [51] In our study, the hospitalized reimbursement ratio of MIUE with CVD patients was $69.8 \%$, while that of the NCMS was only $39.7 \%$, accounting for only half of the MIUE. Urban residents are expected to have a greater awareness of their health and better access to health insurance (especially private health insurance) and hence are more likely to obtain health insurance. The health needs of people in rural areas are not able to be converted into effective medical needs in time due to lower income levels, high medical prices, and inadequate 
medical care, thus bearing the risk of greater CHE. A Chinese study demonstrates that NCMS cannot prevent CHE from happening in poor families but only reduces its incidence in wealthy families [52]. This differentiated design of health care benefits can sometimes lead to social inequalities, often with the same disease, at different costs, and patients with higher socioeconomic status usually enjoy better health insurance and higher service utilization. In rural areas, this should further increase the reimbursement ratio of outpatient and inpatient expenditures to the elderly with CVDs who receive treatment at every kind of hospital [53].

\section{With the inheritance of the traditional concept of} supporting the elderly in China, the larger family size is the protective factor for CHE

First, our results reveal that family size is a protective factor, that is, the larger the family size, the lower the risk of suffering catastrophic health expenditure. This finding is in line with other studies $[54,55]$.

People with CVD can hardly be social workers, which leads to the loss of labor ability. Smaller families lead to less labor, which will decrease the family's ability to resist economic risks and further result in CHE $[56,57]$. Vulnerable individuals with a chronic disease not only have poor financial ability but also pose a health economic burden to their families. More family members make the individual share less.

Second, the concept of family and filial piety is deeply rooted in China's traditional virtue. Supporting the elderly is the responsibility and obligation, which is written in Chinese law. This kind of social culture deeply influences the economic decisions of Chinese families. Families with more members will provide more social and financial support to resist the dilemma of catastrophic health expenditure.

\section{Inequality of different income groups under the same medical insurance system}

Our study indicated that the incidence of CHE in subpoor households with CVD (22.5\%) was higher than 5\% of households with the highest income. Its OOP accounts for $22.1 \%$ of CTP, and the economic burden of disease was higher than that of high-income families by nearly $10 \%$. A similar phenomenon occurred in India. According to the data, India's medical expenditure accounts for only $0.9 \%$ of GDP, which is lower than the $2.8 \%$ of the GDP of less developed countries. However, with only government spending, among the five economic subgroups, the poorest households with less income received only $10 \%$ of medical care, while $20 \%$ of the wealthiest households receive up to $33 \%$ of social subsidies, three times as substantially as the poorest households [58]. The significant burden of disease can lead to difficult family life in low-income groups, which thus fall into the evil cycle of "poor illness due to illness and illness due to poverty."

Poor families are at a greater risk of suffering CHE than well-off families and wealthiest families who receive more medical care subsidies [59-61]. It is unfair to poor families to implement the policy of non-differentiated compensation level and welfare package coverage. The capacity to pay for families with different economic levels should be taken as an important factor in formulating compensation strategies. The key link in the design of medical insurance schemes should be inclined to the poor, such as reducing the threshold of outpatient and inpatient deductible for the poor, expanding the coverage of major disease and chronic diseases, and even helping poor families to pay premiums through medical assistance. Therefore, regardless of the type of medical insurance scheme, priority should be given to the differences in compensation and benefit coverage for families with different economic levels during the process of toplevel design of the medical insurance system.

\section{Inconsistencies between multiple health care systems lead to blind spots in the economic risk protection of individuals and families}

China has established multiple medical security systems, including basic medical insurance, major illness insurance, commercial medical insurance, social medical assistance, and charity assistance. However, the complexity of CVDs and the difference in the income of the population means that various systems have not woven a standard, unified safety net to prevent impoverishment by medical expenses, which is mainly reflected in the following two points.

First, the particularity of CVD can lead to the loss of labor, the indirect cost of nursing expenses, and transportation expenses, and long-term drug maintenance will also increase the economic burden of patients. These neglected indirect costs and drug costs have become blind spots in the economic protection of basic healthcare systems. In our study, elderly cardiovascular patients still have to pay more than half (55.5\%) of their medical expenses after reimbursement by basic medical insurance schemes. Moreover, there is no effective mechanism to connect basic insurance schemes, major disease schemes, and medical assistance insurance systems, resulting in this group of patients falling into poverty after paying for high medical expenses.

Second, our results also show that sub-poor households have the highest incidence of $\mathrm{CHE}$ at $22.5 \%$, and the OOP accounts for $22.1 \%$ of CTP, substantially higher than the poorest households. The medical security system has implemented certain health expense reduction policies for these "extremely poor families" without 
economic sources or micro-income, including lowering the deductible line, increasing the proportion of reimbursement, and improving or eliminating top-up measures. The high-risk marginalized population with an economic income slightly higher than that of the poorest households, which is prone to CHE, has not reached the standard of assistance for supplementary medical assistance and has failed to be covered by a multilevel medical security system.

It is evident that exploring the integration of multilevel medical insurance systems, promoting the complementary functions and overlapping effects of multilevel medical insurance systems, and jointly solving the poverty problems caused by cardiovascular patients have become the target task of the current prevention and treatment process of chronic diseases.

\section{Conclusions}

Our study findings reveal that the incidence of CHE and IME was relatively high among elderly households with CVD patients. The elderly who had poor health satisfaction, combined with other chronic diseases, inpatients, and disabled people, were the high-risk groups for CVD. Medical insurance programs have not reduced the risk of CHE or relieve the financial burden of CVD patients in China, especially the elderly who participate in the NCMS. Therefore, there is an urgent need for Chinese policymakers to improve the accuracy of medical health insurance schemes to target the vulnerable characteristics of elderly cardiovascular patients. While improving the accessibility of health services for cardiovascular patients, the next step should be to focus on achieving another function of the medical health insurance system, which is to maximize the economic protection for vulnerable enrollers and reduce their risk of being trapped in poverty, rather than increasing the risk. It is worth noting that our research has its limitations. First, the data were self-reported, which may make it prone to measurement errors. Second, the study used crosssectional samples rather than panel data, making it difficult to test the long-term effects of health insurance and other control variables on $\mathrm{CHE}$ in cardiovascular patients.

\section{Acknowledgements}

Each author contributed to the concept, design, research, data analysis, drafting of the article,and we acknowledge the outstanding contributions of Wanxin Tian, Jian Kang and Yuze Li who contributed equally to the first author of this article. I have obtained written permission from all persons named in the Acknowledgement.

\section{Authors' contributions}

Conceptualization, Ye Li, Qunhong Wu, Linghan Shan; Data analysis\&Original draft writing,Meiyan Ma,Wanxin Tian,and Yuze Li;Formal analysis, Han Gao, Heng Li,Baoguo Shi and Sun Tao;Literature collection, Qi Xia,Nianshi Wang, Wenqing Miao and Xiyu Zhang:Proofreading,Xuelian Fu and Yanhua Hao;Revision,Wanxin Tian,Jian Kang and Yiyun Zhang;Funding, Linghan
Shan,Qunhong Wu and Ye Li. All authors read and approved the final manuscript.

\section{Funding}

This work was supported by the National Natural Science Foundation (71874045, 71403073,71804036), China Postdoctoral Science Foundation (2016 M590296), Heilongjiang Postdoctoral Foundation (LBH-Z14166), the National Social Science Fund of China (19AZD013), Project supported by the General Undergraduate Colleges and Universities Youth Innovative Talent Training Plan in Heilongjiang Province (UNPYSCT-2020176) and Project of Family Planning Commission of the Department of Health in Heilongjiang Province(2014-427).

\section{Availability of data and materials}

The datasets generated during and/or analyzed during the current study are available in the CHARLS repository, [http://charls.pku.edu.cn/pages/data/111/ zh-cn.html]

\section{Declarations}

Ethics approval and consent to participate

Not applicable

\section{Consent for publication}

Not applicable

\section{Competing interests}

The authors declare that they have no competing interests.

\section{Author details}

${ }^{1}$ Research Center of Public Policy and Management, School of Health Management, Harbin Medical University, Harbin 150086, Heilongjiang, China. ${ }^{2}$ Heilongjiang Provincial Hospital, Harbin, Heilongjiang, China. ${ }^{3}$ Department of Medicine, Jiamusi University, Jiamusi 154007, Heilongjiang, China. ${ }^{4}$ School of Ethnology and Sociology, Yunnan University, Kunming, Yunnan, China.

${ }^{5}$ Department of Economics, School of Economics, Minzu University of China, Beijing, China. ${ }^{6}$ The Affiliated Tumor Hospital of Harbin Medical University, Harbin, Heilongjiang, China. ${ }^{7}$ Department of Health Service Management, School of Medicine, Hang Zhou Normal University, Hangzhou, Zhejiang, China. ${ }^{8}$ The Second Affiliated Hospital of Harbin Medical University, Harbin, Heilongjiang, China. ${ }^{9}$ Hospital Development institute of Shanghai Jiao Tong University, Shanghai, China.

Received: 29 October 2020 Accepted: 4 March 2021

Published online: 29 March 2021

\section{References}

1. Li Y, Wang DD, Ley SH, et al. Potential impact of time trend of life-style factors on cardiovascular disease burden in China. J Am Coll Cardiol. 2016; 68(8):818-33.

2. Tuppin $\mathrm{P}$, et al. Prevalence and economic burden of cardiovascular diseases in France in 2013 according to the national health insurance scheme database. Arch Cardiovasc Dis. 2016:399-411.

3. Hsu WY. A decision-making mechanism for assessing risk factor significance in cardiovascular diseases. Decis Support Syst. 2018;115:64-77.

4. GBD. 2015 Eastern Mediterranean region cardiovascular disease collaborators. Burden of cardiovascular diseases in the eastern Mediterranean region, 1990-2015: findings from the global burden of disease 2015 study. Int J Public Health. 2018;63(Suppl 1):1-13.

5. China Cardiovascular Disease Report 2018. Edited by the National Cardiovascular Center. Beijing: China Encyclopedia Publishing House; 2019 p. 1. https://www.nccd.org.cn/Sites/Uploaded/File/2021/3/\%E4\%B8\%AD\% E5\%9B\%BD\%E5\%BF\%83\%E8\%A 1\%80\%E7\%AE\%A1\%E7\%97\%85\%E6\%8A\%A 5\%E5\%91\%8A2018\%EF\%BC\%88English\%EF\%BC\%89.pdf. Accessed $12 \mathrm{Mar}$ 2021.

6. Zhou M, Wang H, Zhu J, et al. Cause-specifific mortality for 240 causes in China during 1990-2013: a systematic subnational analysis for the global burden of disease study 2013. Lancet. 2016:387:251-72.

7. Al-Mallah MH, Farah I, Al-Madani W, et al. The impact of nurse-led clinics on the mortality and morbidity of patients with cardiovascular diseases: a systematic review and meta-analysis. J Cardiovasc Nurs. 2016;31(1):89. 
8. National Academies of Sciences, Engineering and Medicine. Global Health and the Future Role of the United States: A Report of the National Academies of Sciences, Engineering, and Medicin by the Committee on Global Health and the Future of the United States, Board on Global Health, Health and Medicine Division. Washington, DC: The National Academies Press; 2017.

9. Engelgau MM, Saharty S, Kudesia P, et al. Capitalizing on the demographic transition: tackling noncommunicable diseases in South Asia. Washington, DC: World Bank; 2011

10. Murray CJ, Vos T, Lozano R, et al. Disability-adjusted life years (DALYs) for 291 diseases and injuries in 21 regions,1990-2010: a systematic analysis for the global burden of disease study 2010. Lancet. 2012;380(9859):2197-223.

11. National Center for CVDs of China. Report on CVDs in China (2016). Beijing: Encyclopedia of China Publishing House; 2017.

12. Yusuf S, Reddy S, Anand S. Global burden of cardiovascular diseases part II: variations in cardiovascular disease by specific ethnic groups and geographic regions and prevention strategies. Circulation. 2001;104(23): 2855-64.

13. Australian Institute of Health and Welfare (AlHW). Australia's Health 2014 Australia's Health Series No. 14; Cat. No. AUS 178. Canberra: AlHW; 2014. Published online on February 1 2017. DOI:25816/5ec1e4122547e https:// www.aihw.gov.au/reports/australias-health/australias-health-2014/contents/ table-of-contents .Accessed 21 Aug 2019

14. World Bank: Toward a Healthy and Harmonious Life in China: Stemming the Rising Tide of Non-Communicable Diseases. 2011. Published online on July 26 2011.https://www.worldbank.org/en/news/feature/2011/07/26/towardhealth-harmonious-life-china-stemming-rising-tide-of-non-communicablediseases. Accessed 21 Aug 2019.

15. Li Y, Wu QH, Li CJ, et al. Catastrophic Health Expenditure and Rural Household Impoverishment in China: What Role Does the New Cooperative Health Insurance Scheme Play? PLoS One. 2014;9(4):e93253.

16. Fanourgiakis J, Kanoupakis E. Catastrophic healthcare expenditure during economic recession in the field of cardiovascular disease. Expert Rev Pharm Out. 2014;14(1):5-8.

17. Gupta A, Pradhan B, Maulud KNA. Estimating the impact of daily weather on the temporal pattern of COVID-19 outbreak in India. Earth Syst Environ. 2020;4(3):3.

18. Alkindi KM, Alkharusi A, Alshukaili D, et al. Spatiotemporal assessment of COVID-19 spread over Oman using GIS techniques. Earth Syst Environ. 2020; 4:797-811.

19. Rohrer M, Flahault A, Stoffel M. Peaks of fine particulate matter may modulate the spreading and virulence of COVID-19. Earth Syst Environ. 2020;4:789-96

20. Manoharan R, Alemu M, Legesse B, et al. Malaria Hazard and risk analysis using geospatial techniques in the case of selected Woredas of Jimma zone, Oromia region, Ethiopia. Earth Syst Environ. 2020;5:115-26.

21. Liu $X$, Sun $X$, Zhao $Y$, et al. Financial protection of rural health insurance for patients with hypertension and diabetes: repeated cross-sectional surveys in rural China. BMC Health Serv Res. 2016;16(1):481.

22. Li C, Jian W. Economic burden of cardiovascular disease in middle-aged and elderly people-an empirical analysis based on China's health and pension tracking survey. Chin J Health Policy Res. 2017;10(5):75-80.

23. European Commission. Published online on March 26, 2014.https://ec europa.eu/eurostat/en/web/products-statistical-working-papers. Accessed 21 Aug 2019.

24. World Health Organization. Health Financing Strategy for the Asia Pacific Region (2010-2015). Switzerland: World Health Organization; 2009.

25. Xu K. Distribution of health payments and catastrophic expenditures methodology. Geneva: Department of Health System Financing, World Health Organization; 2005.

26. Wooldridge JM. Further results on instrumental variables estimation of average treatment effects in the correlated random coefficient model. Econ Lett. 2003;79(2):185-91.

27. Jelena A, Milena P, Bernd R, Wim G. Catastrophic Health Care Expenditure among Older People with Chronic Diseases in 15 European Countries. PLoS One. 2016;11(7):e0157765.

28. Lewbel A. Endogenous selection or treatment model estimation. J Econ. 2007;141(2):777-806

29. Wang XW. A study on the impact of health on the labor supply behavior of the mid-aged and elderly of China: Anhui University of Finance and Economics; 2016.
30. Hu HW, Zhang L, Li JY, Du YX, Wang JR. Does urban residents basic medical insurance worsen the medical burden to the elderly?-system evaluation with household medical burden. Chin Sci Res Aging. 2015;4:51-61.

31. Gu NY, Gai Y, Hay JW. The effect of patient satisfaction with pharmacist consultation on medication adherence: an instrumental variable approach. Pharm Pract. 2008;6(4):201-10.

32. Hall AR, Rudebusch GD, Wilcox DW. Judging instrument relevance in instrumental variables estimation. Int Econ Rev. 1996;37(2):283-98.

33. Arsenijevic J. Catastrophic Health Care Expenditure among Older People with Chronic Diseases in 15 European Countries. PLoS One. 2016;11(7): e0157765.

34. Tolla MT, Norheim OF, Verguet, Stéphane, et al. Out-of-pocket expenditures for prevention and treatment of CVD in general and specialised cardiac hospitals in Addis Ababa, Ethiopia: a cross-sectional cohort study. BMJ Glob Health. 2017;2(2):e000280.

35. Ribeiro S, Furtado C, Pereira J. Association between cardiovascular disease and socioeconomic levelin Portugal. Rev Port Cardiol. 2013;32(11):847-54.

36. Ngalesoni FN, Ruhago GM, Mori AT, et al. Equity impact analysis of medical approaches to cardiovascular diseases prevention in Tanzania. Soc Sci Med. 2016;170:208-17.

37. WHO. Health in 2015: from MDGs to SDGs. Geneva: World Health Organization; 2015.

38. Dittrich $L$, Stara D. The impact of aging population on the rise of the health care cost in the Czech Republic. Int Adv Econ Res. 2013;19(1):11-7.

39. Hopman P, Heins MJ, Rijken M, et al. Health care utilization of patients with multiple chronic diseases in the Netherlands: differences and underlying factors. Eur J Intern Med. 2015;26(3):190-6.

40. Cother H, Emma S. The global burden of multiple chronic conditions: a narrative review. Prev Med Rep. 2018;12:284-93. https://doi.org/10.1016/j. pmedr.2018.10.008.

41. Organization for Economic Cooperation and Development. Health at a glance 2013: OECD indicators. Published online on May 26 2015. https://doi. org/10.1787/health_glance-2013-en. Accessed 13 Mar 2021.

42. Lee JE, Shin HI, Do YK, et al. Catastrophic Health Expenditures for Households with Disabled Members: Evidence from the Korean Health Panel. J Korean Med Sci. 2016;31(3):336-44. https://doi.org/10.3346/jkms.201 6.31.3.336.

43. Zuvekas SH, Selden TM. Mental health and family out-of-pocket expenditure burdens. Med Care Res Rev. 2010;67(2):194-212.

44. Gotsadze G, Zoidze A, Rukhadze N. Household catastrophic health expenditure: evidence from Georgia and its policy implications. BMC Health Serv Res. 2009;9(1):69-0.

45. Ministry Of Health, Ministry of Finance \& Affairs, M. O. C. Announcement of the Development of new rural cooperative medical scheme in 2012: China; 2012.

46. Shi X. Locked out? China's health insurance scheme and internal migration. Labour Econ. 2020;67:101931. https://doi.org/10.1016/j.labeco.2020.101931.

47. Yang M. Demand for social health insurance: evidence from the Chinese new rural cooperative medical scheme. China Econ Rev. 2018;52:126-35.

48. Zhao WM. Does health insurance promote people's consumption? New evidence from China. China Econ Rev. 2018;53:65-86. https://doi.org/10.101 6/j.chieco.2018.08.007

49. Yang $W$, Wu $X$. Providing comprehensive health insurance coverage in rural China: a critical appraisal of the new cooperative medical scheme and ways forward. Global Policy. 2017:8(1):110-16.

50. Liu H, Gao S, Rizzo JA. The expansion of public health insurance and the demand for private health insurance in rural China. China Econ Rev. 2011; 22(1):28-41.

51. Li C, Young BR, Jian W. Association of socioeconomic status with financial burden of disease among elderly patients with cardiovascular disease: evidence from the China Health and Retirement Longitudinal Survey. BMJ Open. 2018;8(3):e018703.

52. Guo N, Iversen T, Lu M, et al. Does the new cooperative medical scheme reduce inequality in catastrophic health expenditure in rural China? BMC Health Serv Res. 2016;16(1):653

53. Wang Z, Li X, Chen M. Catastrophic health expenditures and its inequality in elderly households with chronic disease patients in China. Int J Equity Health. 2015:14(1):8.

54. A S V, B A R, A F F K, et al. Decomposition of socioeconomic inequality in catastrophic health expenditure: an evidence from Iran - ScienceDirect. Clin Epidemiol Global Health. 2020;8(2):437-41. 
55. Halliday TJ, Park M. Household size, home health care, and medical expenditures. Working Papers, No.09-16. 2009.

56. Bhojani U, Thriveni BS, Devadasan R, Munegowda CM, Devadasan N, Kplsteren $\mathrm{P}$, et al. Out-of-pocket healthcare payments on chronic conditions impoverish urban poor in Bangalore, India. BMC Public Health. 2012;12:990

57. Bayudan-Dacuycuy C, Lim JA. Family size, household shocks and chronic and transient poverty in the Philippines. J Asian Econ. 2013;29:101-12.

58. Meng $\mathrm{Q}, \mathrm{Xu} \mathrm{L}$, Zhang $\mathrm{Y}$, et al. Trends in access to health services and financial protection in China between 2003 and 2011: a crosses ctional study. Lancet. 2012;379:805-14.

59. Lunga-Lunga F, Leveque A, Laokri S, Dramaix M. Incidence of catastrophic health expenditures for households: an example of medical attention for the treatment of severe childhood malaria in Kinshasa reference hospitals, Democratic Republic of Congo[J]. J Infect Public Health. 2015;8(2):136-44.

60. A Y C, A J S, B C C Z. Income-dependent impacts of health insurance on medical expenditures: theory and evidence from China. China Econ Rev. 2019;53:290-310

61. Wang L, Wang A, Fitzgerald $G$, et al. Who benefited from the new rural cooperative medical system in China? A case study on Anhui Province. BMC Health Serv Res. 2016;16(1):195.

\section{Publisher's Note}

Springer Nature remains neutral with regard to jurisdictional claims in published maps and institutional affiliations.

Ready to submit your research? Choose BMC and benefit from:

- fast, convenient online submission

- thorough peer review by experienced researchers in your field

- rapid publication on acceptance

- support for research data, including large and complex data types

- gold Open Access which fosters wider collaboration and increased citations

- maximum visibility for your research: over $100 \mathrm{M}$ website views per year

At $\mathrm{BMC}$, research is always in progress.

Learn more biomedcentral.com/submissions 